\title{
A review on the young history of the wind power short-term prediction
}

\author{
Alexandre Costa , Antonio Crespo , Jorge Navarro , Gil Lizcano , \\ Henrik Madserı, Everaldo Feitosa
}

\author{
Wind Energy, Division of Renewable Energies, Department of Energy, CIEMAT, Av. Complutense, \\ 22, Ed. 42, 28044 Madrid, Spain \\ Laboratorio de Mecánica de Fluidos, Departmento de Ingenieria Energética y Fluidomecánica, ETSII, \\ Universidad Politécnica de Madrid, C/José Gutiérrez Abascal, 2-28006 Madrid, Spain \\ Oxford University Centre for the Environment, University of Oxford, South Parks Road, Oxford OXI 3QY, UK \\ Informatics and Mathematical Modelling IMM, Technical University of Denmark, Richard Petersens Plads, \\ Building 321, Office 019, 2800 Kgs. Lyngby, Denmark \\ Brazilian Wind Energy Centre-CBEE, Centro de Tecnologia e Geociências, UFPE-50.740-530 Recife, PE, Brazil
}

\begin{abstract}
This paper makes a brief review on 30 years of history of the wind power short-term prediction, since the first ideas and sketches on the theme to the actual state of the art on models and tools, giving emphasis to the most significant proposals and developments. The two principal lines of thought on short-term prediction (mathematical and physical) are indistinctly treated here and comparisons between models and tools are avoided, mainly because, on the one hand, a standard for a measure of performance is still not adopted and, on the other hand, it is very important that the data are exactly the same in order to compare two models (this fact makes it almost impossible to carry out a quantitative comparison between a huge number of models and methods). In place of a quantitative description, a qualitative approach is preferred for this review, remarking the
\end{abstract}


contribution (and innovative aspect) of each model. On the basis of the review, some topics for future research are pointed out.

Keywords: Wind energy; Short-term prediction; Forecasting methods; Models (mathematical); Statistics; Models (physical); Meteorology

\section{Contents}

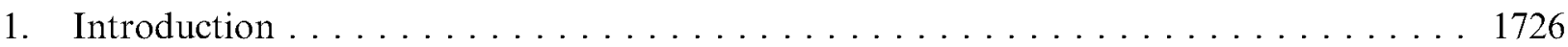

2. Review . . . . . . . . . . . . . . . . . . . . . . . . . . . . . . . . 1727

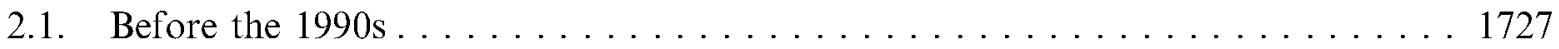

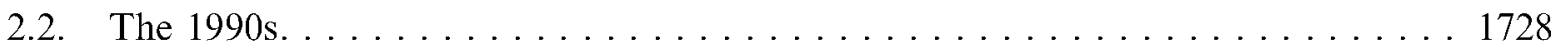

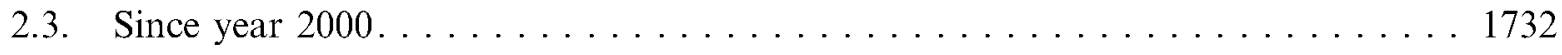

3. Conclusions . . . . . . . . . . . . . . . . . . . . . . . . . . 1739

Acknowledgements . . . . . . . . . . . . . . . . . . . . . . 1740

References . . . . . . . . . . . . . . . . . . . . . . . . . . . . . 1740

\section{Introduction}

Short-term prediction is a subclass of the wind power time prediction (in opposition to the wind power spatial prediction). The time scales concerning short-term prediction are in the order of some days (for the forecast horizon) and from minutes to hours (for the timestep). Its purpose is the prediction of the wind farm output either directly or indirectly (first, estimating the wind and, after, converting it into power). Short-term prediction is mainly oriented to the spot (daily and intraday) market, system management and scheduling of some maintenance tasks, being of interest to system operators, electricity companies and wind farm promoters.

This paper makes a review on the 30 decades of history of the wind power short-term prediction, an extremely important field of research not only for the wind energy sector, but also for the energy sector in general (as the system operators must handle an important amount of fluctuating power from the increasing installed wind power capacity). The review tries to give a clear idea on the chronology and evolvement of the short-term prediction.

Practically, since the beginnings, the short-term prediction has awakened expectation in the electricity sector and its evolution has been fomented by competing commercial interests. As a consequence of this pressing emergent claim about the short-term prediction, the major part of the relevant developments has been published in 'high-speed vehicles' for the communication: the proceedings of expert meetings and conferences.

The comparison of the performance of the prediction models is not evident, mainly because, on the one hand, a standard for a measure of performance is still not adopted and, on the other hand, it is very important that the data are exactly the same in order to compare two models (this fact makes it almost impossible to carry out a quantitative comparison between a huge number of models and methods). Regarding the former question, model performance is assessed in a variety of ways: mean error (ME), mean 
absolute error (MAE), mean square error (MSE), root mean square error (RMSE), improvement over persistence, correlation with real data, etc. For this reason, this review has not the intent of dealing with quantitative descriptions. On the contrary, its purpose is pointing out some of the most representative models and tools developed since the beginnings of the young history of the wind power short-term prediction, while focusing on the main characteristics of the models and tools described in the second section of this paper.

Based on the review, some points for future research are suggested in the third section of this paper.

\section{Review}

\subsection{Before the $1990 \mathrm{~s}$}

One of the first attempts to clarify the importance and advantages of the short-term prediction to the electricity companies was carried out at the ends of the 1970 s, by a discussion group at the Pacific Northwest Laboratory whose conclusions indicated that sufficiently reliable forecasts could have the following applications

- weekly forecasts of day-to-day winds for use in maintenance scheduling;

- daily forecasts of hourly wind levels to be factored into the load scheduling strategy;

- hourly forecasts of expected winds for dispatching decisions.

During the 1980s, the first significant works were published. Notis et al. developed a semi-objective method to predict wind speed $24 \mathrm{~h}$ ahead with an hourly time-step, oriented to load scheduling. The main idea was to refine the output from weather services for a specific site using, for instance, model output statistics (MOS) . Wegley and Formica tested and improved the former approach Wegley et al. predicted wind speed, testing three models (persistence, autoregressive models and generalized equivalent Markov model) for three distinct time-steps $(10,30$ and $60 \mathrm{~min})$. Their conclusion was that persistence and Markov model performed best for the shortest and longest time-steps respectively . Geerts developed a Kalman filter and ARMA models (oriented to the integration of wind energy into the grid) to be proved against persistence, predicting wind speed with a forecast horizon of $24 \mathrm{~h}$ and hourly time-step. With respect to the ARMA models, he indicated that the $k$-step ahead predictor could be determined recursively, starting from the 1-step ahead predictor and measured data up to the actual instant. Tested on a year of data, both models overcame persistence in a forecast horizon of up to $16 \mathrm{~h}$ approximately, giving $\operatorname{ARMA}(2,1)$ better results than the Kalman filter. Motivated by these results, he remarked that, in addition to wind speed, other variables could be employed in order to improve the accuracy (e.g., wind direction, pressure and temperature)

McCarthy predicted for some wind farms in California during the period 1985-1987, using a pocket programmable calculator HP41CX. With a forecast horizon of up to $24 \mathrm{~h}$, the program was based on meteorological observations and local upper air observations, outperforming persistence and climatology for daily average wind speed

Kaminsky et al. based their approach on a definition of different synoptic weather categories. They worked with a time-step of $15 \mathrm{~min}$ to predict wind speed through a regression over the 90 past steps, concluding that the different synoptic weather categories 
required different regression methods Bossanyi applied Kalman filters to predict wind speed with a time-step of $1 \mathrm{~min}$, comparing their performance with persistence. He set the parameters of the model considering only the improvement over persistence for the 1-step ahead forecast over a data set of $1000 \mathrm{~h}$. With the selected parameters for 1-step ahead, a forecast horizon of up to 10 steps was investigated, obtaining an almost constant improvement over persistence for all steps ahead. Also, he generated new series with timesteps (averaged values) of 2,5,10 and $15 \mathrm{~min}$ (starting from the original 1 min data set) in order to study the evolution of the 1-step ahead prediction error (and respective improvement over persistence) with the time-step of the series. In the same way, he averaged two other data sets (from a second distinct site) to produce new series with timesteps from $2 \mathrm{~s}$ to $5 \mathrm{~min}$ and, still,proved (for a third distinct site) 1 year of data with hourly time-step. Based on the limited data available, his main conclusions were that:

(i) the smallest prediction errors occured about a time-step of $5 \mathrm{~min}$;

(ii) the greatest improvement over persistence occured about a time-step of $1 \mathrm{~min}$;

(iii) persistence performed better for hourly data;

(iv) the similarity between the shape of the curve 'improvement versus time-step' (from $2 \mathrm{~s}$ to $15 \mathrm{~min}$ ) and a 'typical wind turbulence spectrum' may not be entirely coincidental.

Finally, he presented applications of the forecasts for furling operations of wind turbines

In the same year, Bossanyi published results for ARMA models predicting wind speed with time-steps of $2 \mathrm{~s}$ and $1 \mathrm{~min}$ and a forecast horizon of up to 10 steps. Getting better performance (over persistence) from the $\operatorname{ARMA}(1,5)$, he referred a slight improvement when determining the $k$-step ahead predictor recursively, starting from the 1 -step ahead predictor and measured data up to the actual instant. Also, he presented applications of the forecasts for wind turbine furling operations and switch-on/switch-off operations of diesel generators in autonomous wind/diesel systems. Bailey and Stewart published one of the first reviews on short-term prediction, resuming the main aspects of the most significant models developed until that moment and pointing out the necessary actions to be carried out in order to obtain an improvement of the models. Mainly, they concentrated their attention on the necessity for data bases at local level and short time intervals and an evaluation, for short-term purposes, of existing data bases such as meteorological monitoring networks, synoptic analysis products, forecast products, climatological analyses and digitized orography

\subsection{The $1990 \mathrm{~s}$}

During the 1990s, the increase of the installed wind energy capacity all over the world (mainly in Europe and United States) attracted the attention of electricity companies, wind farm promoters and researchers towards the short-term prediction, mainly motivated by the necessity of integration into the grid of an increasing 'unknown' (fluctuating) amount of wind power. Troen and Landberg informed about launching a study in the frame of the EC-JOULE Programme involving Danish and British research centres and meteorological services. They presented the Danish activities and some preliminary results. Their proposition was a model based on the refinement of geostrophic wind estimates 
was based on the geostrophic drag law. First results pointed to a slight improvement over persistence for the single value (wind speed and direction) $9 \mathrm{~h}$ ahead, considering only magnitudes greater than $5 \mathrm{~m} / \mathrm{s}$ [14]. Fellows and Hill investigated electrical load prediction (with an hourly time-step and a forecast horizon of up to $6 \mathrm{~h}$ ) and wind turbines output power prediction (with a time-step of $10 \mathrm{~min}$ and a forecast horizon of up to $2 \mathrm{~h}$ ). To predict load, they employed an on-line detrending method, in which the original data were decomposed into annual and diurnal trends and detrended data. The annual and diurnal trends were predicted using persistence and tacking average over a predefined number of past weeks, respectively. The detrended data were predicted by means of an autoregressive model. Regarding the wind turbines output power, they predicted wind using an off-line detrending method and an autoregressive model, converting it into output power through a transfer function. Their result for a markedly seasonal electrical load time series was a considerable improvement over persistence and other 'common-sense methods, such as using the value of the load at the same time the previous day, but scaled to reflect changes in load between days'. For a non-seasonal wind time series, the autoregressive model applied on the original data presented no significant improvement over persistence. In its turn, applied on off-line detrended data, the autoregressive model presented very significant improvement over persistence. At last, they reported preliminary results from a simulation of a wind/diesel system making use of load and wind power forecasts. Their main conclusions were that:

(i) a considerable decreasing of the diesel overload running time was achieved;

(ii) fuel savings were less sensitive to improved wind forecasts than to improved electrical load forecasts;

(iii) persistence predicted the wind better than the load

\section{Watson}

investigated the reduction of fossil fuel costs (from spinning reserve and costly wind turbines start/stop operations), employing numerical weather prediction (NWP) with MOS to predict wind speed and direction with a forecast horizon of up to $18 \mathrm{~h}$ and an hourly time-step. They applied wind forecasts into a simulation of the UK grid system, made through the national grid model of the Reading University and Rutherford Appleton Laboratory. Their conclusion was that the NWP/MOS forecasts can overcome significantly the fossil fuel savings produced by the persistence Continuing this work, Landberg et al. published some improvements and consequent better results Tande and Landberg proved neural networks to predict the output power from a single wind turbine (using wind speed as exogenous variable). Their aim was to predict the single value 10 steps ahead in a time series with $1 \mathrm{~s}$ data. They obtained only a slight improvement over persistence, pointing that further investigations should be carried out before any conclusions about the capability of the model Martin et al. informed about launching a Spanish project involving public and private research centres, a wind turbine manufacturer and electricity companies with the aim of developing an ad hoc operational tool for short-term prediction of local wind conditions and wind farms output at Tarifa, Gibraltar Strait (at that moment, this area already exceeded $40 \mathrm{MW}$ of installed wind energy capacity). With a forecast horizon of up to 3 or 6 days, the operational tool was based on local climatological analysis, local wind regime analysis and wind farms parameterization

Beyer et al. proved neural networks (single perceptron, multilayer perceptron and radial 
basis functions) to predict wind speed and the output power from a single wind turbine, working with time-steps of 1 and $10 \mathrm{~min}$. For wind speed, they achieved approximately the same improvement over persistence for both time-steps and all models (except for the single perceptron predicting at $1 \mathrm{~min}$, in which case the improvement was somewhat smaller). For output power, the wind speed was converted into power through the characteristic curve of a wind turbine. Again, the improvement over persistence for both time-steps and all models was approximately the same (except for the single perceptron, whose improvement was somewhat smaller for both 1 and $10 \mathrm{~min}$ ). Comparing their results with previous publications, they concluded that better results for the considered time scales are probably not possible, because there is no sufficient information on time series (at these time scales) to permit such an enhance. Moreover, they emphasized that simple network architectures give comparable results to more complex approaches at these time scales [20]. Jensen et al. presented the wind power prediction tool (WPPT), developed by the Department of Informatics and Mathematical Modelling (IMM) from the Technical University of Denmark (DTU) and under test at the ELSAM service area, a Danish utility. With a half hourly time-step and a forecast horizon of up to $36 \mathrm{~h}$, the tool was oriented to load dispatching and tested on seven wind farms, being constructed on the basis of an autoregressive model with output power as main variable and wind speed as exogenous variable. The particularities of this model were:

(i) the inclusion of a harmonic term to represent the diurnal pattern;

(ii) a square root transformation of the variables, such that a Gaussian distribution could approximate the distribution of the prediction errors.

They reported the structure of the software, the operational experiences until that moment (data collection began in the first months of 1993), some graphs (real data and predictions) and perspectives for further developments (e.g., including meteorological forecasts as exogenous variables). Also, they mentioned the development of an upscaling method to estimate the total production in the ELSAM service area $(360 \mathrm{MW})$ based on the regarded seven wind farms (almost $40 \mathrm{MW}$ ) Landberg reported some results from the application of the RISØ National Laboratory's model to 17 wind farms of the Danish utility ELKRAFT Madsen published a report describing the experiences of DTU and the utilities ELSAM and SEP with the prediction tool WPPT

In this document, he described various approaches to predict wind farms output power (e.g., predicting power directly or indirectly, considering or neglecting the dependence with the wind direction, models including meteorological forecasts, autoregressive models and neural networks). Also, he described an upscaling method and practical experience with on-line operation. He detailed the best overall model, an autoregressive model with a harmonic term to represent the diurnal pattern and a square root transformation of the variables Kariniotakis et al. investigated neural networks and a fuzzy logic-based approach, getting a better improvement over persistence for the fuzzy model predicting the wind turbines output power within a forecast horizon of up to $2 \mathrm{~h}$ and with a time-step of $10 \mathrm{~min}$. They tested the models with data from a wind/diesel system, considering the wind turbines output power as main variable and the wind speed as exogenous variable. To optimize the model architecture, they employed an algorithm based on the non-linear simplex method of Box, avoiding the usual trial-and-error method. Also, they mentioned the development of an advanced control system in the frame of the 
JOULE II Project. Such a system (making use of wind power forecasts) was installed in a wind/diesel system at the Greek island of Lemnos [24]. Lin et al. studied neural networks to predict wind speed and direction, with a time-step of $1 \mathrm{~s}$. They tried different architectures (one or two hidden layers with different numbers of neurons), different activation functions, different learning methods and different lengths for the training set. They achieved a considerable improvement over an 'optimal' autoregressive model [25]. Akylas et al. tested different approaches (based on meteorological forecasts and recorded data from meteorological masts) to predict wind speed and convert it into wind turbines output power (through measured power curves). With a forecast horizon of up to $24 \mathrm{~h}$ and an hourly time-step, they proved basically three classes of models against the persistence:

(i) multi-variable regression over the time series from meteorological masts, considering wind speed, temperature, pressure and pressure tendency;

(ii) regression of meteorological forecasts over the time series from meteorological masts;

(iii) corrections of meteorological forecasts for microscale effects using wind field simulation.

Their conclusion was that the first class of models slightly overcame persistence, while the second and third classes considerably overcame persistence, with a very small difference in favour of the third class Kariniotakis et al. compared distinct approaches to predict wind turbines output power (naive, neural networks, fuzzy logic, wavelet network and autoregressive model). Within a forecast horizon of up to $2 \mathrm{~h}$ and a time-step of $10 \mathrm{~min}$, they achieved best overall improvement over persistence for the fuzzy logic-based model. The worst performance was achieved for naive and autoregressive model . Bailey et al. presented the tool EWind to predict wind speed and direction, developed by the company TRUEWIND. With a forecast horizon of up to $48 \mathrm{~h}$ and an hourly (or half an hour) time-step, the tool was based on a mesoscale model (ForeWind) which refines the outputs from a regional weather model, trying to track local effects as, for instance, local circulations due to differential heating of the surface. The tool employs a MOS (based on recorded data) for on-line operation. Two approaches are considered to convert wind into wind farm output power, according to the complexity of the situation: purely statistical modelling and physical modelling (e.g., based on wake effects) Beyer et al. developed (at the University of Oldenburg) a model analogous to the RIS $\varnothing$ National Laboratory's model With a forecast horizon of up to $48 \mathrm{~h}$ and a time-step of $6 \mathrm{~h}$, the German model used the wind turbines power curve (from the manufacturer) to convert wind speed forecasts into output power. Employing forecasts from the German weather service's model (Deutschlandmodell), they presented results for six sites at Northern Germany, indicating good predictions within the horizon of up to $24 \mathrm{~h}$. Furthermore, they evaluated the spatial correlation of the prediction deviations, concluding that:

(i) the correlation decreased with an increasing distance;

(ii) the deviations for longer forecast horizons were more correlated than for short ones, because of the 'increased systematic error of the prediction for longer times'

Nielsen et al. showed that it is not reasonable to use the persistence as a reference model within a forecast horizon larger than a few hours. Instead, they proposed a weighting 
between the persistence and the mean of the power, defending it as an adequate reference model for all forecast lengths

\subsection{Since year 2000}

In the last 6 years, special attention has been devoted to the development of tools for online operation and assessment of the uncertainties of forecasts. Also, the first attempts of 'true' integration between the two complementary research lines on short-term prediction (mathematical and physical models) have been carried out. Sfetsos compared linear models (autoregressive models) with non-linear models (feedforward neural networks, radial basis function network, Elman recurrent network, ANFIS models and neural logic network) to predict mean hourly wind speed time series. Evaluating only the 1-step ahead predictor (and putting his attention on the RMSE and the improvement over persistence), he concluded that:

(i) the non-linear models overcame the linear models;

(ii) all the non-linear models presented comparable RMSE;

(iii) the neural logic network was slightly superior to the others

Lange and Waldl presented their conclusions on the uncertainties related to the University of Oldenburg's model

They remarked that:

(i) the uncertainty on wind speed forecast is independent of the magnitude of the predicted wind speed;

(ii) the uncertainty on power forecast is a function of both the power curve and the ME of the related wind speed forecast;

(iii) for some sites, the uncertainty on wind speed forecast presents some dependence on the overall weather situation (e.g., errors are larger for low-pressure systems with frontal zones crossing)

Watson et al. reported preliminary results from the on-line operation of the RISØ National Laboratory's model informed that the first results for 15 wind farms in Ireland were promising, although the model was still not tuned for the specific sites Giebel et al. informed about launching a 3 year project funded by the Danish Ministry of Energy, the objective being an integration of the models Prediktor and WPPT to be employed by all Danish utilities. The final tool (named Zephyr) was planned to get together the advantages of both models. On the one hand, WPPT with better predictions for horizons of up to a quarter of a day, aptitude to extend the meteorological service's forecast horizon and capability of handling changes in the input, as, for instance, changes in the weather model. On the other hand, Prediktor with better predictions for horizons ranging from a quarter of a day to the maximum horizon of the meteorological service and with the possibility of making forecasts even without measurements available. Also, an upscaling module was programmed. The tool was thought to be as flexible and stable as possible, being independent of the platform and of the operational system Marti et al. investigated the refinement of the outputs from the HIRLAM model (with two spatial resolutions, $0.2^{\circ}$ 
and $0.5^{\circ}$ ) for the prediction of output power from a wind farm in Spain, located in a moderately complex terrain. They developed three basic models:

(i) wind speed prediction model;

(ii) power curve model;

(iii) power prediction model.

Regarding the first model (wind speed prediction), three approaches were tested:

(i) interpolation of the four surrounding HIRLAM grid points, using distance as weight factor;

(ii) density corrected wind speed, based on predictions of sea level pressure and $2 \mathrm{~m}$ level air temperature;

(iii) downscaling based on principal components (to select the regressor variables) and multiple regression (principal components over measured $u, v$ velocity components).

Both second and third models (power curve and power prediction) were based on adaptive local polynomial regression, considering the dependence on wind direction. Their conclusions were that:

(i) models based on HIRLAM $0.2^{\circ}$ outperformed models based on HIRLAM $0.5^{\circ}$ in a forecast horizon of up to $24 \mathrm{~h}$;

(ii) for both spatial resolutions $\left(0.2^{\circ}\right.$ and $\left.0.5^{\circ}\right)$, downscaling based on principal components outperformed interpolation and density correction-based models

Focken et al. studied the prediction of the aggregated output power of wind farms over different regions within a forecast horizon of up to $48 \mathrm{~h}$. They observed an important decreasing of the prediction error due to spatial smoothing. Considering 30 wind farms in Germany, they concluded that the reduction in the error is much more sensitive to the size of the region than to the number of sites

At December of 2002, the International Energy Agency (IEA) held the Joint Action Symposium on Wind Forecasting Techniques. Some of the contributions to this symposium were:

- project of Garrad Hassan and partners (co-funded by the UK Government) to develop a tool for wind speed and wind farm output power prediction within a horizon of up to $24 \mathrm{~h}$

- activities report of CENER-CIEMAT Foundation, presenting improvements on its model as the use of the mesoscale model MM5 , and the development of a model for regional forecasts (named RegioPred);

- presentation of the prediction tool Sipreólico, a joint effort of the Universidad Carlos III de Madrid and the Spanish system operator Red Eléctrica de España (REE). By that date, a prototype was installed by REE to be tested in the peninsular power system operation. With a forecast horizon of up to $36 \mathrm{~h}$ and an hourly time-step, the tool was thought to produce forecasts in practically all situations, despite the accuracy. Three main data sets were considered. Considering the basic data set as input (wind turbines 
manufacturer power curves and meteorological forecasts), output power prediction was made on the basis of the wind speed forecasts and the sum of the manufacturer power curves. Considering the additional data set as input (the basic data set plus the measured power curves), better output power prediction could be made, including also wind direction forecasts. Considering the complete data set as input (the basic data set plus on-line measurements), the best output power prediction was possible, through an ensemble of nine mathematical/statistical models (autoregressive models with different architectures, estimated in an adaptive way). The final forecast was a linear combination of the three predictors presenting the lowest exponentially weighted mean-squared prediction error

- experiences with short-term prediction in Canada Norway US Finland Germany Mexico Netherlands Denmark and Sweden

Costa et al. informed about launching the UPMPREDICTION Project, an attempt of 'true' integration between the two complementary research lines on short-term prediction (mathematical and physical models) and development of an operational (on-line) tool oriented to the spot market and power system management. In the first stage of the project, three classes of statistical/mathematical models were tested by the Universidad Politécnica de Madrid and CIEMAT: autoregressive models, fuzzy logic-based models and neural networks. From these models, neural networks achieved better improvement over persistence for three wind farms at the Northwest region of Spain [51]. Palomares and de Castro applied a perfect prognosis statistical downscaling method at the Gibraltar Strait. They employed ECMWF reanalysis data and observed wind data from a meteorological station. Ten different cases were carried out in order to fit the models according to the wind direction and season of the year. Considering a horizon of up to $48 \mathrm{~h}$, their main conclusions were:

(i) the quality of the predictions had not a significant decrease with the horizon;

(ii) the best results were related to the Easterly winds;

(iii) the worst results were related to the calms (smaller than $1 \mathrm{~m} / \mathrm{s}$ )

Lozano presented preliminary results of the developing IBERDROLA's model, a physical model nesting NCEP/NCAR global model and mesoscale/microscale models within a forecast horizon of up to $48 \mathrm{~h}$ and an hourly time-step Kariniotakis et al. informed about launching the ANEMOS Project (under the Fifth Framework Programme of the European Commission), a consortium with institutions from 7 countries (research centres, universities, industry, utilities, system operators, meteorological services and energy agencies from France, Ireland, Spain, Germany, Greece, Denmark and UK) with the aim of developing a prediction system for the large-scale integration of on- and offshore wind farms, considering a forecast horizon of up to $48 \mathrm{~h}$. Also, larger horizons (up to 7 days) were considered for maintenance scheduling purposes. The project was presented with the following division of tasks:

(i) data collection and evaluation of needs;

(ii) off-line evaluation of prediction techniques;

(iii) development of statistical models; 
(iv) development of physical models;

(v) offshore prediction;

(vi) ANEMOS prediction platform development;

(vii) installation for on-line operation;

(viii) evaluation of on-line operation;

(ix) overall assessment and dissemination.

Regarding the models tested in the first phase of the project, some of them were: Armines Wind Power Prediction System (AWPPS), developed in the frame of the MORE-CARE Project Prediktor; WPPT; Zephyr; Previento; LocalPred; Sipreólico; NTUA's prediction model; RAL's prediction model, developed in the frame of the MORE-CARE Project; ARIA Technologies' prediction model. These models were proved on sites with distinct types of terrain and under distinct climatic conditions Martí et al. informed about an experiment of joining the tools LocalPred and Sipreólico in order to enhance forecasts from Sipreólico, using as inputs the downscaled outputs from LocalPred. This experiment pointed to a clear improvement for a wind farm in complex terrain Gallardo et al. informed about launching the CASANDRA Project, collaboration between the Universidad de Castilla-La Mancha, Barlovento Recursos Naturales and Gamesa Energía. With a forecast horizon of up to $72 \mathrm{~h}$ and an hourly time-step, the prediction tool was based on a mesoscale model (getting data from the NCEP global model), a MOS and a power curve model. This latter model was based on a multivariate regression over wind farm data (e.g., wind speed and direction, pressure and temperature), MOS corrected winds and other variables from the mesoscale model. The tool was thought to offer to the user confidence levels on the predictions in the form of risk figures for taking decisions. Authors presented preliminary results for two wind farms in Spain (located in moderately and complex terrain) and commented the intent of improving the performance of the model with ensemble techniques Giebel et al. and Landberg et al. published two reviews on the state of the art of the different lines of thought about short-term prediction and developing tools

At June of 2004, IEA held the Second Joint Action Symposium on Wind Forecasting Techniques. Some of the contributions to this symposium were:

- Kariniotakis informed about the on-going development of the ANEMOS Project He remarked the tasks carried out since the beginning of the project (e.g., development of end-user requirements, data standardization and software specifications; set-up of eight cases, one being off-shore; benchmarking of 10 prediction systems on the test cases; evaluation of different NWP models, including high resolution; development of innovative methods for uncertainty assessment and prediction risk; progress about the ANEMOS software; planning on on-line installations)

- Costa et al. informed about some improvements in the UPMPREDICTION models (introduced in [51]), results from a collaboration of the Universidad Politécnica de Madrid and CIEMAT with the Department of IMM from the DTU and the Brazilian Wind Energy Centre (CBEE). For two wind farms at the Northeast region of Spain, the fuzzy logic-based models outperformed all other models within a forecast horizon of up to $10 \mathrm{~h}$ and with an hourly time-step. Apart from these improvements, the authors also informed about the on-going development of a physical/meteorological model to be 
integrated with the mathematical/statistical ones. Being based on downscaling of geostrophic wind estimates, the physical model was thought to be firstly adjusted with meteorological reanalysis data and, after, tuned for operation with meteorological forecast data ;

- Giebel published a brief review on short-term prediction models and informed about progresses of the task group responsible by the standard IEC 61400-25 communications for monitoring and control of wind power plants, whose objective is the unification of all data within (from and to) a wind farm. According to Giebel, the standard makes data acquisition easier for short-term prediction purposes. Nevertheless, the standard still does not consider any topic specifically oriented to short-term prediction

- Nielsen proposed methods for transforming global meteorological wind ensembles into wind power ensembles and how to establish a correct set of quantiles. Also, he commented the availability of predictions within a horizon of up to 7 days, using ECMWF and NCEP ensembles as input to statistical models

- experiences with short-term prediction in Norway Ireland and US

Madsen et al. presented a protocol for standardizing the performance evaluation of short-term prediction models, remarking that the use of the persistence as a reference model leads to slightly misleading (overoptimistic) conclusions about the performance of the model in question. They reported the employment of the proposed protocol on the ANEMOS' data base and gave emphasis to the need of improvements on the methods for uncertainty assessment Jiménez et al. studied the sensitivity of wind simulations made by the weather research and forecasting model (WRF) with respect to domain size, frequency supply of the lateral boundary conditions (LBC), planetary boundary layers (PBL) schemes and spatial resolution on the basis of a forecast horizon of up to $72 \mathrm{~h}$ and an hourly time-step. They considered a complex terrain area about $100 \times 100 \mathrm{~km}^{2}$ at the Iberian Peninsula and two distinct synoptic situations, one with fast and another with slow lateral boundary error propagation. They concluded that:

(i) the wind simulations were slightly influenced by the lateral boundary error propagation;

(iii) they were more sensitive to the PBL employed than to domain size and frequency supply of the LBC;

(iii) increasing the horizontal resolution improved the simulations

Bustamante et al. investigated hourly wind speed prediction, considering two approaches: autoregressive models and neural networks for time series; two downscaling methods (dynamical and statistical) for very short-range time scales. The statistical downscaling was based on data from the ERA40 reanalysis project employing principal components (to remove redundant information in the data) and finding analogous patterns to be linearly regressed over real observations. The last part of the study consisted of a dynamical downscaling, made through a mesoscale model (MM5). Their conclusion was that 'a statistical downscaling, which combines atmospheric fields simulated by some reanalysis project, like ERA15 or ERA40, over a dynamic downscaling with a regional or mesoscale model to reach better resolutions for predictions improves obtained results' Pinson and Kariniotakis presented a methodology to assess (on-line) the risk related to wind power forecasts. They employed the resampling approach to 
generate the confidence bands. They introduced the meteo-risk index (which gives an idea on the spread of NWPs) to be used in the adjustment of the confidence bands. Also, they proposed the employment of the meteo-risk index as an indicator about the probability of the occurrence of high prediction errors (according to the weather stability) [75]. Kariniotakis et al. presented partial results from the ANEMOS Project. Based on six wind farms distributed in the Northern and Western regions of Europe (one offshore, two in onshore flat terrain, two in complex terrain and one in highly complex terrain), they concluded that, among other things:

(i) the NWP spatial resolution was of major importance especially in complex terrain;

(ii) the performance of the models had a dependence on the complexity of the terrain, being less accurate in complex terrain;

(iii) the prediction model errors were more dispersed in complex terrain;

(iv) not any model at all prevailed all over the steps ahead;

(v) the combination of different predictions should be tried in order to reduce the error.

The qualitative comparison between the different models was performed on the basis of the 12-h ahead predictions, taking into account that not all the models were applied for all the wind farms and that different validation periods were considered [76]. Moliner informed about an exercise (by that date, in progress) launched by the Plataforma Empresarial Eólica (PEE), a forum of the Spanish wind industry, whose object was to assess different short-term prediction tools. The exercise consisted of a comparison between 7 tools on six Spanish wind farms. The main objectives were:

(i) to define the maximum forecast horizon (on the basis of an hourly time-step) for short-term prediction of wind farms output;

(ii) to assess the influence of the orography on the accuracy of the tools;

(iii) to evaluate the costs and payback regarding the tools for individual wind farms.

Also, the Spanish electricity market operator (OMEL) took part in the exercise with a simulation of sales in the spot (daily and intraday) market Torres et al. published results for ARMA models applied for wind speed prediction, with an hourly time-step and a forecast horizon of up to 10 steps ahead. Considering a study on 9 years of data from 5 different measurement stations, they presented an off-line approach to transform and standardize the time series in order to make the distribution approximately Gaussian and to avoid seasonality. Adjusting one model for each one of the 12 months of the year, they achieved significant improvements over persistence on the RMSE basis, observing that the RMSE presented a certain dependence on the wind speed values Madsen et al. emphasized the necessity for a standard methodology to assess the performance of the models. They proposed a set of guidelines with respect to performance measures. For instance, they recommended the normalized bias, normalized MAE and normalized RMSE as the minimum set of error measures to be considered, these measures being given per step ahead. They suggested that the error measures should be evaluated not only over the whole test set, but also over smaller periods (for example, in order to observe monthly variations in the performance of the models). Also, they mentioned that the most appropriate performance measure depends on the intended application Nielsen et al. proposed a method to build a model of the quantiles of the prediction error inspired in the 
works

Employing linear quantile regression and parametric additive models, they investigated models for the lower and upper quartiles, considering the following regressor variables: forecasted power from WPPT, forecast horizon and forecasts from HIRLAM operated by the Danish Meteorological Institute (air density, friction velocity, wind speed $10 \mathrm{~m}$ AGL and wind direction $10 \mathrm{~m} \mathrm{AGL).} \mathrm{Also,} \mathrm{they} \mathrm{studied}$ the influence of a risk index inspired in the work Their main conclusions were:

(i) the most relevant variable was the forecasted power;

(ii) the risk index seemed to have no influence on the studied quartiles;

(iii) the additive model approach was adopted because it allows for inclusion of many regressor variables

Ceña presented the final conclusions Considering an extension of the number of prediction tools and wind farms ( 8 prediction tools and seven wind farms in Spain: two at the coast, one in onshore flat terrain, two in complex terrain and two in highly complex terrain), the exercise was completed after 13 months with the following main conclusions:

(i) the accuracy had a dependence on the wind speed level (low winds were associated with lower precision);

(ii) there seemed to be a lower limit of $25 \%$ (hard to beat with the available data and actual techniques) for the MAE normalized by the monthly mean power;

(iii) contrary to the common sense, the terrain seemed to have no influence on the quality of the forecasts;

(iv) the output from different wind farms should be aggregated in order to reduce the prediction error;

(v) persistence could be more accurate than the other models within a very short horizon;

(vi) depending on the NWPs used as input, the statistical models have shown to be sufficient

At February of 2006, a workshop to present conclusive results from the ANEMOS Project was held during the European Wind Energy Conference. Some of the contributions to this meeting were:

- Kariniotakis et al. gave an overview of the project, emphasizing that the final software was installed with evaluation purposes for on-line operation at some on- and offshore wind farms. They mentioned plans for the elaboration of guidelines for the optimal use of wind prediction systems. Also, they indicated references containing detailed information on the results from the project

- Waldl et al. pointed out some aspects based on their experiences with the on-line operation of the ANEMOS platform (a software for the integration of the forecasts from all the prediction models) during more than 1 year

- Martí et al. discussed the results from a study about the dependence of the distribution of the prediction errors on the level of the predicted power, taking into account the first four moments of the distribution (bias, standard deviation, skewness and kurtosis). Also, they discussed the performance of a proposed method for combining the forecasts 
from all prediction models, based on a two-step procedure (in the first step, an optimal linear combination of the forecasts was performed; in the second step, the best forecast was selected over all forecasts including the combination made in the first step)

- detailed results from some other specific tasks within the project were discussed: statistical models physical models and offshore prediction

Costa et al. informed about the project

They proposed a mechanism to integrate both mathematical/statistical and physical/meteorological models. This mechanism (called 'best intersection point tracking', shortly b.i.tracking) was based on a combination of the forecasts starting from a tracking of the intersection point between the error curves of the models. After this tracking, the idea was to minimize the error of the final model, giving more emphasis to time series-based models below the tracked intersection point and more emphasis to meteorological forecasts-based models beyond the referred point. Regarding the physical/meteorological models, they proposed a sectorial discretization of the problem, in which the microscale orographic corrections and stability (non-neutral regime) corrections were applied only for those sectors where these corrections were capable of decreasing the prediction error. At last, they mentioned their intention to extend the proposed physical/meteorological models with a dynamic downscaling through mesoscale models (MM5, WRF)

One of the ultimate initiatives towards the integration of the two main lines of thought in the short-term prediction (mathematical and physical models) is the recent launching of the IN-VENTO Project, partially funded by the Spanish Ministry of Education and Science. Joining 1 public research centre (CIEMAT), 5 universities (Universidades de Cantabria, Complutense de Madrid, de Murcia, del País Vasco, Politécnica de Madrid) and some collaborators (URV, URJC, Consorcio de Aguas Bilbao Bizkaia, GKSS from Germany, IMM-DTU from Denmark), this project has the aim of a truthful interchange of the generated knowledge between its members and a complete diffusion of this knowledge to the society (through a set of articles in journals and conferences and the publication of a conclusive 'White Book'). Among other things, the following tasks will be carried out:

(i) the development of a quality control procedure for the data base;

(ii) development of a reanalysis on the Iberian Peninsula, integrating a surface model and data assimilation techniques;

(iii) short- and middle-range wind power forecasting (up to $48-72 \mathrm{~h}$ ) as well as seasonal forecasting (up to 1 month) in complex terrain;

(iv) statistical and dynamical downscaling approaches;

(v) microscale study;

(vi) statistical and physical power curve modelling;

(vii) economic study.

\section{Conclusions}

This review tries to give a clear idea on the chronology and evolvement of the short-term prediction. Some lessons can be learned from this review. From these lessons, some topics 
(unsolved, poorly exploited or, even, unexploited yet) are clearly identified as an urgent need for the feasibility of operational (on-line) tools, such as, for instance:

- adoption of a standard for measurement of performance of models;

- improvement of the accuracy of existing models and tools;

- methods which are able to provide reliable estimates of the uncertainty of the predictions from deterministic models;

- development of probabilistic models (e.g., Bayesian networks, ensemble forecasts-based models);

- further research on the adaptive parameter estimation, since the models have to automatically adopt to changes in the farm and in the surroundings;

- integration between mathematical/statistical and physical/meteorological models such that the final model indeed takes advantage from the higher accuracy of time seriesbased models in shorter horizons and advantage from the wider forecast horizons of physical/meteorological models, increasing the spatial and time resolution of the meteorological services to take into account local phenomena;

- development of more accurate upscaling methods;

- development of more accurate downscaling methods;

- new approaches on complex terrain (e.g., more accurate-and computationally feasible-turbulence closure models for microscale tools).

\section{References}

Wendell L, Wegley $\mathrm{H}$, Verholek M. Report from a working group meeting on wind forecasts for WECS operation. PNL-2513, Pacific Northwest Laboratory, 1978.

Bailey B, Stewart R. Wind forecasting for wind power stations. In: Galt J, editor. Proceedings of wind energy conversion, Edinburgh, UK, 1987. p. 265-9.

Notis C, Trettel D, Aquino J, Piazza T, Taylor L, Trask D, et al. Learning to forecast wind at remote sites for wind energy applications. PNL-4318, Pacific Northwest Laboratory, 1983.

Wegley $\mathbf{H}$, Formica $\mathrm{W}$. Test applications of a semi-objective approach to wind forecasting for wind energy applications. PNL-4403, Pacific Northwest Laboratory, 1983.

Wegley H, Kosorok M, Formica W. Subhourly wind forecasting techniques for wind turbine operations. PNL-4894, Pacific Northwest Laboratory, 1984.

Geerts H. Short range prediction of windspeeds: a system-theoretic approach. In: Palz W, editor. Proceedings of European wind energy conference, Hamburg, Germany, 1984. p. 5949.

Giebel G. Short-term prediction-overview and taxonomy. In: Proceedings of the second joint action symposium on wind forecasting techniques. Lyngby, Denmark: International Energy Agency (IEA); 2004. Kaminsky F, et al. Time series models of average wind speed within synoptic weather categories. In: Proceedings of the fourth ASME wind energy symposium; 1985. p. 215-9.

Bossanyi E. Short-term wind prediction using Kalman filters. Wind Eng 1985;9(1):1-8.

Bossanyi E. Stochastic wind prediction for turbine system control. In: Proceedings of the seventh British wind energy association conference, Oxford, UK, 1985.

Bossanyi E. Short-term stochastic wind prediction and possible control applications. In: Proceedings of the Delphi workshop on wind energy applications; 1985. 
Bailey B, Stewart R. Wind forecasting for wind power stations. In: Proceedings of the ninth British wind energy association conference, Edinburgh, 1987.

Machenhauer B. HIRLAM Final Report. HIRLAM Technical Report 5, Copenhagen, Denmark, 1988. Troen I, Landberg L. Short term prediction of local wind conditions. In: Proceedings of European community wind energy conference, Madrid, Spain, 1990. p. 76-8.

Fellows A, Hill D. Wind and load forecasting for integration of wind power into a meso-scale electrical grid. In: Proceedings of European community wind energy conference, Madrid, Spain, 1990. p. 636 40.

Watson S, Halliday J, Landberg L. Assessing the economic benefits of numerical weather prediction model wind forecasts to electricity generating utilities. In: Clayton B, editor. Proceedings of wind energy conversion, Nottingham, UK, 1992. p. 291-7.

Landberg L, Watson S, Halliday J, Jørgensen J. Short-term prediction of local wind conditions. In: Garrad A, Palz W, Scheller S, editors. Proceedings of European community wind energy conference, LübeckTravemünde, Germany, 1993. p. 677-9.

Tande J, Landberg L. A $10 \mathrm{sec}$ forecast of wind turbine output with neural networks. In: Garrad A, Palz W, Scheller S, editors. Proceedings of European community wind energy conference, Lübeck-Travemünde, Germany, 1993. p. 774-7.

Martin F, Zubiaur R, Moreno P, Rodríguez S, Cabre M, Casanova M, et al. Operational tool for short term prediction model of energy production in wind power plants at Tarifa (Spain). In: Garrad A, Palz W, Scheller $\mathrm{S}$, editors. Proceedings of European community wind energy conference, Lübeck-Travemünde, Germany, 1993. p. 802-3.

Beyer H, Degner T, Hausmann J, Hoffmann M, Ruján P. Short term prediction of wind speed and power output of a wind turbine with neural networks. In: Tsipouridis J, editor. Proceedings of European wind energy conference, Thessaloniki-Macedonia, Greece, 1994. p. 349-52.

Jensen U, Pelgrum E, Madsen H. The development of a forecasting model for the prediction of wind power production to be used in central dispatch centres. In: Tsipouridis J, editor. Proceedings of European wind energy conference, Thessaloniki-Macedonia, Greece, 1994. p. 353-6.

Landberg L. Implementing wind forecasting at a utility. In: Tsipouridis J, editor. Proceedings of European wind energy conference, Thessaloniki-Macedonia, Greece, 1994. p. 357-60.

Madsen H. Models and methods for predicting wind power. Denmark: IMM, ELSAM, SEP; 1996.

Kariniotakis G, Nogaret E, Stavrakakis G. A fuzzy logic and a neural network based wind power forecasting model. In: Zervos A, Ehmann H, Helm P, editors. Proceedings of European union wind energy conference, Göteborg, Sweden, 1996. p. 596-9.

Lin L, Eriksson J, Vihriälä H, Söderlund L. Predicting wind behaviour with neural networks. In: Zervos A, Ehmann H, Helm P, editors. Proceedings of European union wind energy conference, Göteborg, Sweden, 1996. p. 655-8.

Akylas E, Tombrou M, Panourgias J, Lalas D. The use of common meteorological predictions in estimating short term wind energy production in complex terrain. In: Watson R, editor. Proceedings of European wind energy conference, Dublin Castle, Ireland, 1997. p. 329-32.

Kariniotakis G, Nogaret E, Stavrakakis G. Advanced short-term forecasting of wind power production. In: Watson R, editor. Proceedings of European wind energy conference, Dublin Castle, Ireland, 1997. p. $751-4$. Bailey B, Brower M, Zack J. Short-term wind forecasting-development and application of a mesoscale model. In: Proceedings of European wind energy conference, Nice, 1999.

Beyer H, Heinemann D, Mellinghoff H, Mönnich K, Waldl H. Forecast of regional power output of wind turbines. In: Proceedings of European wind energy conference, Nice, 1999.

Nielsen T, Joensen A, Madsen H, Landberg L, Giebel G. A new reference for wind power forecasting. Wind Energy 1999;1:29-34.

Sfetsos A. A comparison of various forecasting techniques applied to mean hourly wind speed time series. Renewable Energy 2000;21:23-35.

Lange M, Waldl H. Assessing the uncertainty of wind power predictions with regard to specific weather situations. In: Proceedings of European wind energy conference, Copenhagen, 2001.

Watson R, Landberg L, Costello R, McCoy D, O'Donnell P. Evaluation of the Prediktor wind power forecasting system in Ireland. In: Proceedings of European wind energy conference, Copenhagen, 2001.

Giebel G, Landberg L, Nielsen T, Madsen H. The Zephyr-Project - the next generation prediction system. In: Proceedings of European wind energy conference, Copenhagen, 2001.

Martí I, Nielsen T, Madsen H, Navarro J, Roldán A, Cabezón D, et al. Prediction models in complex terrain. In: Proceedings of European wind energy conference, Copenhagen, 2001. 
Focken U, Lange M, Monnich K, Wald1 H, Beyer H, Luig A. Short-term prediction of the aggregated power output of wind farms - a statistical analysis of the reduction of the prediction error by spatial smoothing effects. J Wind Eng Ind Aerodyn 2002;90(3):231-46.

Gow G. Short term wind forecasting. In: Proceedings of the first joint action symposium on wind forecasting techniques. Norrköping: International Energy Agency (IEA); 2002.

Grell G, Dudhia J, Stanffer D. A description of the fifth-generation Penn State/NCAR mesoscale model (MM5). NCAR Technical Note, NCAR/TN 3981 STR, 1995.

Sánchez I, Usaola J, Ravelo O, Velasco C, Domínguez J, Lobo M, et al. Sipreólico-a wind power prediction system based on flexible combination of dynamical models. Application to the Spanish power system. In: Proceedings of the first joint action symposium on wind forecasting techniques. Norrköping: International Energy Agency (IEA); 2002.

Benoit R, Yu W. Developing and testing of wind power forecasting techniques for Canada. In: Proceedings of the first joint action symposium on wind forecasting techniques. Norrköping: International Energy Agency (IEA); 2002.

Berge E. Experiences with wind forecasting techniques in Norway. In: Proceedings of the first joint action symposium on wind forecasting techniques. Norrköping: International Energy Agency (IEA); 2002.

Bremnes J. Probabilistic wind power forecasts by means of statistical model. In: Proceedings of the first joint action symposium on wind forecasting techniques. Norrköping: International Energy Agency (IEA); 2002. Westrick K. Wind energy forecasting in the Pacific Northwestern U.S. In: Proceedings of the first joint action symposium on wind forecasting techniques. Norrköping: International Energy Agency (IEA); 2002.

Schwartz M, Milligan M. Statistical wind forecasting at the US, National Renewable Energy Laboratory. In: Proceedings of the first joint action symposium on wind forecasting techniques. Norrköping: International Energy Agency (IEA); 2002.

Tammelin B. Wind power forecasting by FMI. In: Proceedings of the first joint action symposium on wind forecasting techniques. Norrköping: International Energy Agency (IEA); 2002.

Ernst B, Rohrig K. Online-monitoring and prediction of wind power in German transmission system operation centres. In: Proceedings of the first joint action symposium on wind forecasting techniques. Norrköping: International Energy Agency (IEA); 2002.

Borja M, Jaramillo O, Miranda U. Prospects for the application of wind forecasting techniques in La Ventosa, México. In: Proceedings of the first joint action symposium on wind forecasting techniques. Norrköping: International Energy Agency (IEA); 2002.

Brand A, Kok J. Wind power by a quarter of the hour. In: Proceedings of the first joint action symposium on wind forecasting techniques. Norrköping: International Energy Agency (IEA); 2002.

Holttinen H, Nielsen T, Giebel G. Wind energy in the liberalised market - forecast errors in a day-ahead market compared to a more flexible market mechanism. In: Proceedings of the first joint action symposium on wind forecasting techniques. Norrköping: International Energy Agency (IEA); 2002.

Törnkvist M. Vattenfall \& wind energy forecasts. In: Proceedings of the first joint action symposium on wind forecasting techniques. Norrköping: International Energy Agency (IEA); 2002.

Costa A, Crespo A, Migoya E. First results from a prediction project. In: Proceedings of European wind energy conference, Madrid, 2003.

Palomares A, de Castro M. Short-term wind prediction model at the Strait of Gibraltar based on a perfect prognosis statistical downscaling method. In: Proceedings of European wind energy conference, Madrid, 2003.

Kalnay E, et al. The NCEP/NCAR 40-year reanalysis project. Bulletin of the American Meteorological Society 1996;77:437-71.

Lozano T. Prediction and planning of wind energy production. In: Proceedings of European wind energy conference, Madrid, 2003.

Hatziargyriou G, Matos M, Lopes J, Kariniotakis G, Mayer D, Halliday J, et al. 'MORE CARE' advice for secure operation of isolated power systems with increased renewable energy penetration and storage. In: Proceedings of European wind energy conference, Copenhagen, 2001.

Kariniotakis G, Mayer D, Moussafir J, Chevallaz-Perrier R, Usaola J, Sánchez I, et al. ANEMOS: development of a next generation wind power forecasting system for the large-scale integration of onshore \& offshore wind farms. In: Proceedings of European wind energy conference, Madrid, 2003.

Martí I, Usaola J, Sánchez I, Lobo M, Navarro J, Roldán A, et al. Wind power prediction in complex terrain. LocalPred and Sipreólico. In: Proceedings of European wind energy conference, Madrid, 2003. 
Gallardo C, Gaertner M, Tejeda C, Martínez N, Calabria S, Martínez N, et al. The Casandra project: first results of a new wind power operational forecasting system in Spain. In: Proceedings of European wind energy conference, Madrid, 2003.

Giebel G, Landberg L, Kariniotakis G, Brownsword R. State-of-the-art on methods and software tools for short-term prediction of wind energy production. In: Proceedings of European wind energy conference, Madrid, 2003.

Landberg L, Giebel G, Nielsen H, Nielsen T, Madsen H. Short-term prediction - an overview. Wind Energy 2003;6:273-80.

Kariniotakis G. ANEMOS: development of a next generation wind power forecasting system for the largescale integration of onshore \& offshore wind farms 2002-2006. In: Proceedings of the second joint action symposium on wind forecasting techniques. Lyngby: International Energy Agency (IEA); 2004.

Costa A, Crespo A, Feitosa E, Navarro J, Jiménez P, García E, et al. Mathematical and physical wind power forecasting models: a proposal for the UPMPREDICTION project. In: Proceedings of the second joint action symposium on wind forecasting techniques. Lyngby: International Energy Agency (IEA); 2004.

Giebel G. Short-term prediction-overview and taxonomy. In: Proceedings of the second joint action symposium on wind forecasting techniques. Lyngby: International Energy Agency (IEA); 2004.

Giebel G. The IEC task for wind farm communication and its implications on the short-term forecasting community. In: Proceedings of the second joint action symposium on wind forecasting techniques. Lyngby: International Energy Agency (IEA); 2004.

Nielsen H. Wind power ensemble forecasting. In: Proceedings of the second joint action symposium on wind forecasting techniques. Lyngby: International Energy Agency (IEA); 2004.

Berge E. Forecasting the energy production for Norwegian wind farms. In: Proceedings of the second joint action symposium on wind forecasting techniques. Lyngby: International Energy Agency (IEA); 2004.

Bremnes J. Probabilistic forecasts of power production using local quantile regression. In: Proceedings of the second joint action symposium on wind forecasting techniques. Lyngby: International Energy Agency (IEA); 2004.

Ryan M, Walsh L. Wind generation in the Irish system. In: Proceedings of the second joint action symposium on wind forecasting techniques. Lyngby: International Energy Agency (IEA); 2004.

Schwartz M, Schwartz B, Brundage K. Forecasting wind energy application of a NOAA weather forecast model. In: Proceedings of the second joint action symposium on wind forecasting techniques. Lyngby: International Energy Agency (IEA); 2004.

Madsen H, Kariniotakis G, Nielsen H, Nielsen T, Pinson P. A protocol for standardizing the performance evaluation of short-term wind power prediction models. In: Proceedings of global windpower conference and exhibition, Chicago, 2004.

Michalakes J, Chen S, Dudhia J, Hart L, Klemp J, Middlecoff J, et al. Development of a next generation regional weather research and forecast model. Developments in teracomputing, In: Proceedings of the ninth ECMWF workshop on the use of high performance computing in meteorology, Singapore, 2001.

Jiménez P, et al. Sensitivity of MM5 wind prediction to domain size and PBL schemes. In: Proceedings of European wind energy conference, London, 2004.

Simmons A, Gibson J. The ERA-40 Project Plan. ERA-40 Project Report Series 1. Reading: ECMWF; 2000. Bustamante E, Cofiño A, Navarro J, Gutiérrez J, Roldán A. Wind speed downscaling combining mesoscale and neural autoregressive models. In: Proceedings of European wind energy conference, London, 2004.

Pinson P, Kariniotakis G. On-line assessment of prediction risk for wind power production forecasts. Wind Energy 2004;7:119-32.

Kariniotakis G, Martí I, Casas D, Pinson P, Nielsen T, Madsen H, et al. What performance can be expected by short-term wind power prediction models depending on site characteristics? In: Proceedings of European wind energy conference, London, 2004.

Moliner M. Predicción del viento: España toma la delantera. Energías Renovables 2004;28:20-2.

Torres J, García A, De Blas M, De Francisco A. Forecast of hourly average wind speed with ARMA models in Navarre (Spain). Sol Energy 2005;79:65-77.

Madsen H, Pinson P, Kariniotakis G, Nielsen H, Nielsen T. Standardizing the performance evaluation of short-term wind power prediction models. Wind Eng 2005;29(6):475-89.

Nielsen $\mathrm{H}$, Madsen $\mathrm{H}$, Nielsen T. Using quantile regression to extend an existing wind power forecasting system with probabilistic forecasts. Wind Energy 2006;9:95-108.

Ceña A. Avanzando en la gestionabilidad (Advancing in manageability). In: Eólica 2006 (Wind power 2006). Madrid: Asociación Empresarial Eólica; 2006. p. 81-7. 
Kariniotakis G, Halliday J, Brownsword R, Martí I, Palomares A, Cruz I, et al. Next generation short-term forecasting of wind power - overview of the ANEMOS project. In: Proceedings of European wind energy conference, Athens, 2006.

Waldl I, Dierich F, Kariniotakis G, Bocquet A, Virlot S. The ANEMOS wind power forecasting platform technology - techniques and experiences. In: Proceedings of European wind energy conference, Athens, 2006. Martí I, Kariniotakis G, Pinson P, Sánchez I, Nielsen T, Madsen H, et al. Evaluation of advanced wind power forecasting models - results of the ANEMOS project. In: Proceedings of European wind energy conference, Athens, 2006.

Nielsen T, Madsen H, Nielsen H, Pinson P, Kariniotakis G, Siebert N, et al. Short-term wind power forecasting using advanced statistical methods. In: Proceedings of European wind energy conference, Athens, 2006.

Giebel G, Badger J, Martí I, Louka P, Kallos G, Palomares A, et al. Short-term forecasting using advanced physical modeling - the results of the ANEMOS project. In: Proceedings of European wind energy conference, Athens, 2006.

Tambke J, von Bremen L, Barthelmie R, Palomares A, Ranchin T, Juban J, et al. Short-term forecasting of offshore wind farm production - developments of the ANEMOS project. In: Proceedings of European wind energy conference, Athens, 2006.

Costa A, Crespo A, Navarro J, Palomares A, Madsen H. Modelling the integration of mathematical and physical models for short-term wind power forecasting. In: Proceedings of European wind energy conference, Athens, 2006. 